\title{
THE INFLUENCE OF THE INTEGRATED MODEL OF SOCIAL STRATIFICATION STRUCTURE ON THE PUBLIC PARTICIPATING NON-PROFIT ORGANIZATIONS
}

\author{
${ }^{1}$ Yu-Tien Huang and ${ }^{2}$ Ming-Shen Wang \\ ${ }^{1}$ Graduate Institute of Public Affairs Management at Transworld University, Taiwan \\ ${ }^{2}$ Institute of Public Affairs Management at National Sun-Yat-Sen University, Kaohsiung, Taiwan
}

Received 2014-01-10; Revised 2014-01-10; Accepted 2014-01-23

\begin{abstract}
The main body of social stratification structure in Taiwan is transformed with social mobility. By transforming the social stratification structure, the function of non-profit organizations is operating steadily. How does people's awareness of social strata directly or indirectly influence the operation of non-profit organizations? How do non-profit organizations and governments respond to the transformation of social stratum compositions? And how promotion and policy marketing could guide the general public to be attentive and participate in the operations of non-profit organizations? These questions require in-depth investigation. This study bases on the experiments and concepts of fairness measurement in information integration theory to comprehend the integrated model of social stratification in the public. By means of analyzing the awareness and orientation of the public to the constitution of social stratification which lead the public to identify themselves with the visions of non-profit organizations and the motion of participating non-profit matters to provide the interrelated recommendations of proceeding non-profit matters to non-profit organizations and the government. Comparing the cognitive algebraic functions of input information and outcome information of various groups in the social strata, the only difference is that if the input information is education background and the outcome information profession prestige. Empirically, non-profit organizations promoting and encouraging people to engage in occupational aid related activities could find different methods available.
\end{abstract}

Keywords: Information Integration Theory, Non-Profit Organization, Social Stratification

\section{INTRODUCTION}

As are Western advanced societies, Taiwanese society is experiencing rapid social shifts including population transformation and modernization. Additionally, the social stratification structure changes significantly with social mobility. For example, the number of non-profit organizations has increased and the number of employees or citizens participating in nonprofit departments gradually grows. These organizations play an ever increasingly important role in socioeconomic aspects and the establishment and systems of non-profit organizations gradually change with the compositions of social strata.
The renowned U.S. based think tank, The Aspen Institute, organized a conference in July, 2001, discussing methods to increase the quality of non-profit and charitable research, as well as to enhance interdisciplinary methodologies applicable to this field. In social studies, critical issues for non-profit organization research are as follows (Guan, 2002):

- How do non-profit organizations promote/impede social mobility?

- How do non-profit organizations deepen/mitigate social inequality?

- How do non-profit organizations illustrate the microscopic/macroscopic relationships between individuals and the social structure as a whole? 
- How do non-profit organizations explain their legitimacy, trust and actual goals, as well as solve issues of diverse voter groups?

- In the field of public policy, how does sociology focus on inequality and resource control?

Issues 3 and 5 are related to the transformation of social stratum compositions in the social structure. From the perspective of sociology, individual behavior can be deeply influenced by the social structure and frequent role interaction occurs in interpersonal relationships. However, how does people's awareness of social strata directly or indirectly influence the operation of non-profit organizations? How do nonprofit organizations and governments respond to the transformation of social stratum compositions? And how promotion and policy marketing could guide the general public to be attentive and participate in the operations of non-profit organizations? These questions require in-depth investigation.

In the 1940 and $1950 \mathrm{~s}$, when children told their parents that the school wanted them to make "donations" to an "orphanage", most parents would collect and donate things that were old and broken in their houses. This kind of participation is passive and inactive. On the contrary, in contemporary Taiwan, some citizens are active in identifying with and participating in charitable events. That non-profit organizations can appropriately and timely develop their power and gain adequate resources of support is not so much caused by the significant improvement in citizens' education as by improvements in economy, social development and social foundational conditions. The progress of Taiwan's social welfare development may be slower than Western countries; in recent years, non-profit organizations obtain increasingly more attention as a provider of social welfare (Lu and Pan, 2004).

Non-profit organizations endeavor to direct the general public's attention to adequate groups or issues in response to the demands of people. Moreover, the positive expectations of such organizations should be responded. However, from what perspective should non-profit organizations and governments should work together on and promote their projects? This study discussed this question from the perspective of social stratification structures because this perspective is totally different from the passive concept prevalent in the 1940 and 1950 s.
Therefore, this study adopted The Information Integration Theory (IIT) to conduct an in-depth analysis on the social strata of the citizens. Through the evaluative analysis on the awareness and orientation of Taiwan's social stratification structure from the aspects of input (family and education background) and outcome (income and profession prestige), on what types of non-profit organizations and issues the particular focus of the participating groups is projected can be understood. In other words, the awareness and orientation of Taiwan's social stratification structure, which influence people's identification with the prospects of non-profit organizations and their enthusiasm with non-profit activities, could be analyzed. The results could provide non-profit organizations and governments with strategies and suggestions for promoting non-profit activities.

\section{MATERIALS AND METHODS}

\subsection{Information Integration Theory (IIT)}

IIT was proposed by Anderson et al. (1996). This theory is based on Thurstone's theory of psychological measurement, verified and supported by the empirical research of Anderson et al. (1996). Therefore, its validity in psychological measurement has been established.

The foundation of the IIT is that human behaviors have purpose. In order to achieve this purpose, people will conceptualize thoughts and actions. Meanwhile, individuals may made different value judgment of information based on different contexts and targets. They may also determine approach-avoidance behavior (Anderson, 1974; 1996). This approachavoidance behavior shows the positive and negative value relevant to the target. This single dimensional description could be applied to statistically analyze complicated behaviors. IIT proposed functional measurement approach to measure the value of these behaviors. On the other hand, IIT views judgment reaction as a integrated outcome of multiple stimulus and reactions, which is so called multiple determination. In order to solve the problems of multiple determinations, IIT proposed a cognitive algebra to integrate these multiple determinants.

According to the verification of Anderson, the cognitive algebra of IIT includes the following three types. 


\subsection{Adding Model}

The factor chart presented a parallel pattern, taking tow stimulus variables as examples, the integration Equation (1) was:

$$
\mathrm{r}_{\mathrm{ij}}=\mathrm{s}_{\mathrm{A}_{\mathrm{ij}}}+\mathrm{s}_{\mathrm{B}_{\mathrm{ij}}}
$$

If the external reaction value $\mathrm{R}$ and psychological reaction value were linearly related, Equation (2) would be true. Putting (1) to (2) then came Equation (3). As for the factor chart produced by factor design, the distance between the corresponding points in the first and second line $(i=1,2)$ was shown in Equation (4). Since $\mathrm{sA}_{1}$ and $\mathrm{sA}_{2}$ were existent psychological values (IIT assumes that psychological value is independent, unchangeable to the objective value $S$ it is combined with), the distance among the three corresponding points in the first and second line was a constant, which meant the two lines were parallel. Even the first and second line is changed into first and third, or second and third, the parallel result will remain:

$$
\begin{aligned}
& \mathrm{R}_{\mathrm{ij}}=\mathrm{C}_{0}+\mathrm{C}_{1}\left(\mathrm{r}_{\mathrm{ij}}\right) \\
& \mathrm{R}_{\mathrm{ij}}=\mathrm{C}_{0}+\mathrm{C}_{1}\left(\mathrm{~s}_{\mathrm{A}_{\mathrm{ij}}}+\mathrm{s}_{\mathrm{B}_{\mathrm{ij}}}\right) \\
& \mathrm{R}_{1 \mathrm{j}}-\mathrm{R}_{2 \mathrm{j}}=\left[\begin{array}{l}
\left.\mathrm{C}_{0}+\mathrm{C}_{1}\left(\mathrm{~s}_{\mathrm{A}_{1}}+\mathrm{s}_{\mathrm{B}_{1 j}}\right)\right]- \\
{\left[\mathrm{C}_{0}+\mathrm{C}_{1}\left(\mathrm{~s}_{\mathrm{A}_{2}}+\mathrm{s}_{\mathrm{B}_{2 \mathrm{j}}}\right)\right.}
\end{array}\right]=\text { constant } \\
& =\mathrm{C}_{1}\left(\mathrm{~s}_{\mathrm{A}_{\mathrm{ij}}}-\mathrm{s}_{\mathrm{B}_{\mathrm{ij}}}\right)
\end{aligned}
$$

The observable parallel chart supported the adding rule, linear reaction measurement and that each stimulus variable is a linear scale. In the adding model, besides its parallel factor chart, the interaction is not significant in the analysis of statistical variance. This indicated that each stimulus variable in the decision was an independent function.

To adopt the adding model means to add all the subjective value of positive information. If it is intended to enhance the subjects' perception level, a higher psychological scale could be used, or they should be provided with more positive information.

\subsection{Averaging Model}

The integration equation was:

$$
\begin{aligned}
& \mathrm{r}_{\mathrm{ij}}=\left(\mathrm{W}_{0} \mathrm{~S}_{0}+\mathrm{W}_{\mathrm{A}_{\mathrm{i}}} \mathrm{s}_{\mathrm{A}_{\mathrm{i}}}+\mathrm{W}_{\mathrm{B}_{\mathrm{j}}} \mathrm{S}_{\mathrm{B}_{\mathrm{j}}}\right) /\left(\mathrm{W}_{0}+\mathrm{W}_{\mathrm{A}_{\mathrm{i}}}+\mathrm{W}_{\mathrm{B}_{\mathrm{j}}}\right) \\
& \mathrm{R}_{1 \mathrm{j}}-\mathrm{R}_{2 \mathrm{j}} \\
& =\mathrm{C}_{1} \mathrm{~W}_{\mathrm{A}}\left(\mathrm{S}_{\mathrm{A} 1}-\mathrm{S}_{\mathrm{A} 2}\right) /\left(\mathrm{W}_{0}+\mathrm{W}_{\mathrm{A}}+\mathrm{W}_{\mathrm{B}}\right)=\text { Constant }
\end{aligned}
$$

Averaging model can be classified into equalweight averaging model and differential-weight averaging model. These two models differ in whether different levels' weights of the same factor are different. When the integration model is differentialweight averaging model, the verification method is basically similar to that of the adding model. When the factor design chart is fan-shaped, the main effect and interaction effect of the analysis of the variance are both significant. Furthermore, the interaction effect is focused on the linear $\times$ linear component, while the other high level interaction components are insignificant. The primary judgment rules were explained in the section of adding rules. When the integration model is equal-weight averaging model, these two lines should be parallel, same with the adding model. In order to differentiate these two, IIT has provided a critical test to examine if it is averaging model.

The critical test is to put together the factor chart of single factor and that of two factors and to observe whether these two charts are intersected. With a parallel factor chart and no interaction in the analysis of the variance, it could be either adding or equalweight averaging model. However, if the critical test found them intersected, it is ensured to be equalweight averaging model instead of adding model. When two lines are intersected, the effects caused by the increased information are not equal, expunging adding model, since in adding model, tow lines should be parallel. In order to more precisely confirm whether the line of a single factor and that of two factors are intersected, further statistical inspection should be made. The software of FM\#1 was used to conduct the analysis of the variance so as to judge the interaction effect.

When the policy maker sued adding model as the information integration model, the total effect or satisfaction level were simultaneously determined by the sum of effect value and relative weight product provided by the evaluation. Also, the effect value and relative weight could both be influenced by the evaluation level in the project. Therefore, when the evaluation objective 
value is increased, the rise of total effect value might come either from the rise of effect value, or from the rise of relative weight. When it is the relative weight but not effect value that had influence, it is not significant for the policy maker and might reduce the overall effect.

\subsection{Multiplying Model}

The factor chart was linear fan-shaped, whose integration Equation (5-7) was:

$$
\begin{aligned}
& \mathrm{r}_{\mathrm{ij}}=\mathrm{s}_{\mathrm{A}_{\mathrm{i}}} * \mathrm{~s}_{\mathrm{B}_{\mathrm{j}}} \\
& \mathrm{R}_{\mathrm{ij}}=\mathrm{C}_{0}+\mathrm{C}_{1} \mathrm{~s}_{\mathrm{A}_{\mathrm{i}}} \mathrm{s}_{\mathrm{B}_{\mathrm{j}}} \\
& \mathrm{R}_{1 \mathrm{j}}-\mathrm{R}_{\mathrm{lj}}=\mathrm{C}_{1} \mathrm{~S}_{\mathrm{Bj}}\left(\mathrm{S}_{\mathrm{A} 1}-\mathrm{s}_{\mathrm{A} 2}\right)=\mathrm{C}_{2} \mathrm{~S}_{\mathrm{Bj}}
\end{aligned}
$$

The observable fan-shaped chart supported the adding rule, linear reaction measurement and that each stimulus variable is a linear scale. It also showed the same meaning of multiple information and that evaluation and integration were independent. The main effect and interaction effect in the analysis of variance were both significant, with the interaction effect centered on the "linear $\times$ linear component". Other components were all insignificant.

Basically, the approach to verify the differentialweight averaging model was the same to that for adding model. The factor design was fan-shaped, the main effect and interaction effect were both significant, with the interaction effect centered on the "linear $\times$ linear component" and the other high-level interaction components were all insignificant. In order to help researchers the distinguish adding model and differential-weight averaging model, Shanteau (1984) proposed three judgment principles, including the attributes of the problem, whether it has standard attribute and the number of factor levels.

When the integration model was adding model, the perception level was determined by the product of variables. Among the combinations of variables, certain variable was of special weight. In other words, when the scale of certain variable was raised by a unit, the total perception level was increased by a unit multiplying the scale values of other levels. When the scale value of certain variable in the adding model was extremely low, it was difficult to increase the scale value of other variables to raise the perception level. The most efficient method is to raise its own scale value.

\section{RESULTS}

Based on IIT, this research adopted an empirical approach to investigate the study of cognitive algebra rule in social aspects. According to the literature, the discrimination standards include education, family background, profession, power, social status, income, prestige and so on. These variables formed a net relationship and can influence each other. This research took the perspective of fairness measurement, with the previous dedications as input and current status-quo as output. Hence, the input variables included education and family background (such as educational backgrounds of parents and family, profession and income). The outcome variables included profession prestige (power resulted from the profession) and income (power resulted from money). We analyzed under different situations, whether there would be discrepancy in different groups for the cognitive integration rule of different inputs and outcome levels in social stratification.

In the experiment, the subjects were divided into two groups. Each participant was received two input variables (with three levels respectively) and two production variables (with two levels respectively). Thus, the variable design of this experiment consisted of input information $(2 \times 3) \times$ production information $(2 \times 2)$.

\subsection{Input Information}

There were two types of input information, one was education background, including low-educated (below junior high school, as well as uneducated), regular-educated (high school to college) and highly educated (above postgraduate school). The other variable was family background, which mainly explored the social stratification parents or family belonged to, such as their educational backgrounds, incomes and profession prestige. It was divided into high living standard (parents or family were at least university graduates), middle living standard (parents or family have attended elementary school to high school and had regular income or profession prestige) and low living standard (uneducated parents who have low incomes and low profession prestige).

\subsection{Outcome Information}

Outcome information also includes two factors. On is profession prestige, such as the social status and 
power generated by a profession, the acknowledgement of the public on the profession and the degree of specialty in the profession. We also adopted the profession categorization proposed by Wen and Chang (1982) in their examination of profession prestige and the social practicality of a profession. In terms of level design, we include high profession prestige (who score higher in the abovementioned aspects, such as professionals, entrepreneurs and government officers) and low profession prestige (who score lower in the abovementioned aspects, such as workers, street vendors and staff in the service industry).

The other variable is income level. This variable is based on the "the average income of the receiver is the disposable income" proclaimed by the Budget, Accounting and Statistics Department, Ministry of Administration of Taiwan. It was equally divided into five parts from the least to the most. The former $20 \%$ was 227,199 NTD and the latter $20 \%$ was $1,248,832$ NTD. Therefore in the level design, the lowest income was the annual disposable income of 200,000, whereas the highest income was the annual disposable income of 1,200,000.

\subsection{Subjects}

We adopted the stratification of two different groups, management and labor group, to analyze whether the existent stratification would influence cognitive rule or not. Management group included those who would directly influence organization performance, have policy-making abilities and serve management positions, such as company managers and school deans. Labor group included those who did not have real management power and who did not have significant balancing power, such as regular employees and waiters. There were 20 Subjects chose from each group via a convenient sampling approach.

\subsection{Findings}

This research adopted the variable figure discrimination and statistical inspection provided by the information integration experiments to examine the integration rule of the subjects. We mainly employed the variable figure charted by EXCEL 2007 to conduct a simple visual inspection. Also, we adopted Shanteau (1984) FM\#1 software to quantify and statistically analyze the cognitive algebra rules used by the subjects and analyze variables so as to observe the significance of the main effect, based on which to judge their integration rules. The findings were presented as Table 1.

Table 1. The information integration model of the group

\begin{tabular}{|c|c|c|c|c|c|c|c|c|c|}
\hline \multirow[b]{2}{*}{$\begin{array}{l}\text { Situation } \\
\text { Subject }\end{array}$} & & \multicolumn{2}{|c|}{$\begin{array}{l}\text { Education background- } \\
\text { profession prestige }\end{array}$} & \multicolumn{2}{|c|}{$\begin{array}{l}\text { Education background- } \\
\text { income }\end{array}$} & \multicolumn{2}{|c|}{$\begin{array}{l}\text { Family background- } \\
\text { profession prestige }\end{array}$} & \multicolumn{2}{|c|}{$\begin{array}{l}\text { Family background- } \\
\text { income }\end{array}$} \\
\hline & & $\begin{array}{l}\text { Management } \\
\text { group }\end{array}$ & $\begin{array}{l}\text { Labor } \\
\text { group }\end{array}$ & $\begin{array}{l}\text { Management } \\
\text { group }\end{array}$ & $\begin{array}{l}\text { Labor } \\
\text { group }\end{array}$ & $\begin{array}{l}\text { Management } \\
\text { group }\end{array}$ & $\begin{array}{l}\text { Labor } \\
\text { group }\end{array}$ & $\begin{array}{l}\text { Management } \\
\text { group }\end{array}$ & $\begin{array}{l}\text { Labor } \\
\text { group }\end{array}$ \\
\hline & df & F-RATIO & F-RATIO & F-RATIO & F-RATIO & F-RATIO & F-RATIO & F-RATIO & F-RATIO \\
\hline Education background & 2 & $83.80 * *$ & $135.60 * *$ & $2.69 * *$ & $0.77 * *$ & -- & -- & -- & -- \\
\hline Family background & 2 & -- & -- & -- & -- & $442.07 * *$ & $442.89 * *$ & $2.74^{*}$ & $3.33 * *$ \\
\hline Profession prestige & 1 & $26.52 * *$ & $64.76^{* *}$ & -- & -- & $218.50 * *$ & $260.64 * *$ & -- & -- \\
\hline income & 1 & -- & -- & $95.49 * *$ & $162.31 * *$ & -- & -- & $800.76^{* *}$ & $860.46^{* *}$ \\
\hline $\begin{array}{l}\text { Education background } \\
\text { profession prestige }\end{array}$ & 2 & $3.66^{*}$ & 1.17 & -- & -- & -- & -- & -- & -- \\
\hline $\begin{array}{l}\text { Education background } \\
\times \text { income }\end{array}$ & 2 & -- & -- & $68.61 * *$ & $113.06 * *$ & -- & -- & -- & -- \\
\hline $\begin{array}{l}\text { Family background } \times \\
\text { profession prestige }\end{array}$ & 2 & -- & -- & -- & -- & 2.40 & 2.28 & -- & -- \\
\hline $\begin{array}{l}\text { Family background } \times \\
\text { income }\end{array}$ & 2 & -- & -- & -- & -- & -- & -- & $552.09 * *$ & $202.02 * *$ \\
\hline Linear $\times$ linear & 1 & $0.11^{*}$ & 0.00 & $76.26 * *$ & $15.07 * *$ & 2.64 & 2.29 & $1169.03 * *$ & $163.47 * *$ \\
\hline $\begin{array}{l}\text { Discrimination of } \\
\text { variable figure }\end{array}$ & & -- & parallel & -- & -- & parallel & parallel & -- & -- \\
\hline Model & & $\begin{array}{l}\text { differential- } \\
\text { weight } \\
\text { averaging } \\
\text { model }\end{array}$ & $\begin{array}{l}\text { adding } \\
\text { model }\end{array}$ & $\begin{array}{l}\text { differential- } \\
\text { weight } \\
\text { averaging } \\
\text { model }\end{array}$ & $\begin{array}{l}\text { differential- } \\
\text { weight } \\
\text { averaging } \\
\text { model }\end{array}$ & $\begin{array}{l}\text { adding } \\
\text { model }\end{array}$ & $\begin{array}{l}\text { adding } \\
\text { model }\end{array}$ & $\begin{array}{l}\text { differential- } \\
\text { weight } \\
\text { averaging } \\
\text { model }\end{array}$ & $\begin{array}{l}\text { differential- } \\
\text { weight } \\
\text { averaging } \\
\text { model }\end{array}$ \\
\hline
\end{tabular}




\section{DISCUSSION}

It is a collective responsibility for people to participate in non-profit organizations. To increase the efficacy, non-profit activities, therefore, should correspond to citizens' anticipation and should promote, mobilize and expect people's participation. According to the IIT, if the adopted integrated model is a different-weight averaging model, the research could focus on a single factor because changes in any factor may significantly affect the perceived inequality. Thus, non-profit organizations that consider issues of two factors should promote and encourage different groups to participate in non-profit organizations and activities. The following sections are discussions of the research results.

\subsection{Discussion on the Influence of Management Groups' Social Stratification Integrated Model on Non-Profit Organization Operation}

The three integrated models (1) educational background and occupation reputation, (2) educational background and income and (3) family background of management groups are different-weight averaging models and family background and profession prestige are adding models. In short, since the integrated models are all different-weight averaging models, non-profit organizations and governments, when attempting to encourage management groups to participating in non-profit activities, could promote the single factor, guiding management groups to participate by stimulating their feelings. The following non-profit organizations can be most effective in holding promotional events:

- Education oriented: Learning assisting volunteers in communities or remote regions

- Occupation oriented: Occupational assistance, aid, training for physically or mentally disabled people.

- Income oriented: Taxation reform groups and trade unions

- Family background oriented: Family counseling association, children welfare group (e.g., abused children assistance), elderly care group and skipgeneration family group

Family background and profession prestige are related to adding models. Thus, these two factors can be incorporated with subjects and activities such as unemployment aid and occupational training.

\subsection{Discussion on the Influence of Labor Groups' Social Stratification Integrated Models on Non-Profit Organization Operation}

The educational background, profession prestige, family background and profession prestige are related to adding models, allowing the following non-profit organizations to stimulate labor groups' perceived inequality and promote them to participate in related activities:

- Concerned with educational background coupled with profession prestige: Occupational training and cooperative education

- Concerned with family background coupled with profession prestige: Unemployment aid and occupational training

The educational background, income and family background are related to different-weight averaging models, allowing the following non-profit organizations to stimulate labor groups' perceived inequality and promote them to participate in related activities:

- Education oriented: Learning assisting volunteers in communities or remote regions

- Income oriented: Taxation reform groups and trade unions

- Family background oriented: Family counseling association, children welfare group (e.g., abused children assistance), elderly care group and skipgeneration family group

In summary, apart from common issues, the difference between management and labor groups is as follows:

- Management groups focus more on occupation related issues than labor groups

- Labor groups focused more on issues that combine educational background and profession prestige than management groups

\subsection{Other Research Implications}

From the aforementioned research results, people's perceived inequality can be transformed into cognitive algebraic functions through experiments. These functions 
could reflect the existence of the perceived inequality in various social strata.

Comparing the cognitive algebraic functions of input information and outcome information of various groups in the social strata, the only difference is that if the input information is education background and the outcome information profession prestige, the management groups show a different-weight averaging model, whereas the labor groups an adding model. The management groups consider that the two information entries affect each other and any of the two entries would significantly influence the perceived inequality, whereas the labor groups do not validate such an influence. It is not difficult to speculate that commonly the management groups are higher in education backgrounds. Empirically, non-profit organizations promoting and encouraging people to engage in occupational aid related activities could find different methods available. For example, for management groups that emphasize education and occupation, organizations could promote cooperative education programs held by universities and college; for academically outstanding students whose family economy is poor, aids can be provided; for dropouts in labor groups, care and employment consulting could be provided.

\section{CONCLUSION}

Taiwan's social stratification structure is experiencing a moderate change. Thus, research on social mobility or stratum comparison for Western societies is highly valuable for observation and reference. In the U.S., citizens' participation in nonprofit organization operation is more than common and becomes even a necessary part of citizenship behavior. Although the systems and laws for non-profit organizations are more and more compact and complete, people's participation awaits to be improved. Moreover, in Taiwan, social stratification has evolved from ethnicity or class stratification to the contemporary division of functions. This evolution matches the arguments proposed by Davis and Moore (1945): People are born unequal and differentiation and professionalization are inevitable in the process of social evolution. However, unequal treatments for different groups will incur a general sense of inequality in the society. These inevitable phenomena, in fact, are beneficial for the promotion of non-profit organizations and governments.

In Taiwan, the economy gradually develops, the industrial structure transforms, the population structure transforms, social perspectives turn to be diverse and open and basic living conditions see an increasing tendency. Moreover, information and education are not available to all, people become more active and enthusiastic in participating in public affairs and oppositions between values of different social classes and strata are being mitigated. All these contribute to the reduction of stratum conflicts caused by education background, family background, profession and income. A cooperative and socially equal state is on the horizon for the benefits of promoting non-profit organization operation.

\subsection{Research Limitations}

A review of the process and contents of this study reveals the following limitations waiting to be overcome:

- The participants mostly belonged to either management or labor groups and they were restricted to the middle class. If the experiments evaluation equality could be extended to other strata, the results will have higher explanatory power

- The excessive number and rigid form of question items overwhelmed the patience of the participants. Questionnaire filling needed to be guided. The sample was small and the time spent was long. Therefore, the experiment could not adopt random sampling

- Limited by the research design, several uncertain factors that might also influence social strata were ignored. Social stratum input and outcome were classified as limited factors that inevitably limited this research

- This research was based on IIT experiments, which provided more understanding about methodologies of cognitive integration as well as meticulous analysis methods to build up internal validity. In addition, foreign empirical studies verify the external validity of our experiments (Marshall and Lee, 1995). Thus, the same procedures can still be used for prospective studies to investigate external validity

\subsection{Prospective Research Directions}

- Through literature review, this study compiled and analyzed input and outcome variables. However, preventing the participants from being overly confused, we did not conduct an integrated factor analysis on intra-input and intra-outcome factors. We suggest future researchers could conduct such analysis

- This research was based on IIT experiments, which provided more understanding about 
methodologies of cognitive integration as well as meticulous analysis methods to build up internal validity. In addition, foreign empirical studies verify the external validity of our experiments (Marshall and Lee, 1995). Thus, the same procedures can still be used for prospective studies to investigate external validity

- The present research only discussed the implications of applying social stratification models to practical affairs based on the results of IIT experiments. In the future, in-depth expert interviews (e.g., empirical workers in non-profit organizations and social work groups) and empirical experiences could be included to support or correct relevant suggestions

\section{REFERENCES}

Anderson, N.H., 1974. Cognitive algebra: Integration theory applied to social attribution. Adv. Exp. Soc. Psychol., 7: 1-101. DOI: 10.1016/S00652601(08)60035-0

Anderson, N.H., 1996. A Functional Theory of Cognition. 1st Edn., Psychology Press, ISBN-10: 0805822445, pp: 500 .
Davis, K. and W.E. Moore, 1945. Some principles of stratification. Am. Sociol. Rev., 10: 242-249. DOI: $10.2307 / 2085643$

Guan, Y.Y., 2002. Research on the third sector: Examining from the perspectives of economics and sector relation theories. Taiwanese J. Soc. Welfare, 2: 1-28.

Lu, C.H. and F.T. Pan, 2004. Transformation of nonprofit organizations: A case study on Sacred Heart Home. Taiwanese J. Soc. Welfare, 3: 79-116.

Marshall, R. and C.K.C. Lee, 1995. Toward the external validity of the information integration paradigm.. Adv. Consumer Res., 22: 78-83.

Shanteau, J., 1984. Functional Measurement Number One Manual for Program FM\#1. Kansas State University, Manhattan.

Wen, C.Y. and X.C. Chang, 1982. The Practicality of Occupational Reputation for Occupations and Societies. In: The Human Resource Development in Taiwan, Yu, Z.X. (Ed.), Institute of Economics, Academia Sinica, Taipei, pp: 565-568. 